\title{
Effect of Household Solid Waste on Initial Growth Performance of Acacia auriculiformis and Cedrela toona in Mycorrhiza Inoculated Soil
}

\author{
M.M. Abdullah-Al-Mamun ${ }^{1 *}$, M. Billah ${ }^{2}$, M.A. Hossain ${ }^{1}$ and M. Alamgir ${ }^{1}$ \\ ${ }^{1}$ Institute of Forestry and Environmental Sciences, University of Chittagong, Chittagong-4331, \\ Bangladesh \\ ${ }^{2}$ CREL Project, Winrock International, South-west regional Office, Khulna-9100, Bangladesh
}

Date Received: 08-01-2015 Date Accepted: 31-03-2015

\begin{abstract}
Solid waste disposal and management became one of the major environmental concerns in Bangladesh. Realising the problem, the present study has been undertaken with a view to find a sound and effective way of bio-degradable solid waste management. The study was carried out in the nursery of Institute of Forestry and Environmental Sciences at University of Chittagong to determine the effects of solid waste and waste inoculated with mycorrhizal soil on initial growth performance of Acacia auriculiformis and Cedrela toona. Before planting the seedlings, decomposable waste and mycorrhiza inoculated decomposable waste were placed on the planting holes. Physical growth parameters of seedlings (shoot and root length, leaf and branch number, fresh and dry weight of shoot and root and nodulation status) and the macro nutrients (N, P and K) were recorded after six months of planting. The highest performance of physical parameters was recorded in the soil treated by mycorrhiza inoculated waste. Cedrela toona was represented by maximum nutrients uptake (N-2.60\%, P-0.21\% and K-2.34\% respectively) in the soil treated with mycorrhiza. In case of Acacia auriculiformis, $\mathrm{N}$ uptake was maximum $(3.02 \%)$ in control while $\mathrm{K}$ uptake was highest $(1.27 \%)$ in soil with waste and $\mathrm{P}(0.18 \%)$ uptake was highest in the soil treated with mycorrhiza inoculated waste. Highest initial growth performance was revealed by seedlings treated with mycorrhiza inoculated waste. This study suggested to use mycorrhiza and waste for plantation purposes for hygienic disposal of solid waste and to reduce cost of cultivation.
\end{abstract}

Keywords: solid waste, mycorrhiza, growth performance, Cedrela toona, Acacia auriculiformis.

\section{Introduction}

Urban solid waste management (SWM) is considered to be one of the most serious environmental problems confronting urban areas especially in developing countries like Bangladesh (Sinha and Enayetullah, 2000; Sujauddin et al., 2007). According to available statistics, 16,380 tons of waste gets produced in Bangladesh per day. Municipal authorities are generally responsible for SWM in Bangladesh (Sujauddin et al., 2007). However, municipal services in most cities and towns are already over-burdened and simply cannot cope with the growing demand owing to insufficient

Correspondence: mamun@cu.ac.bd

Tel: +881712100611

ISSN 2235-9370 Print/ISSN 2235-9362 Online ㄷ University of Sri Jayewardenepura 
Man power and materials, resulting in unhygienic and filthy living condition in the neighborhood (Kumar and Bhowmick, 1998; Enayetullah et al., 2005). However, many of these waste materials can be reused (Kumar and Bhowmick, 1998) and eventually become valuable resources (World Bank, 1999). Among the different types of solid wastes, residential or household waste represents about $30 \%$ of the overall municipal waste stream and the urban residents generate two to three times as much solid waste as their fellow rural citizens in Asia (World Bank, 1999). A substantial portion (69-77\%) of solid waste in the urban areas of Bangladesh is compostable (includes food, vegetable, rags, jute, wood, grass, leaves, etc.). However, the most potential source of compostable waste is residential or household solid waste (Enayetullah et al., 2005; Sujauddin et al., 2007).

Organic materials in solid waste contain nutrients for crop growth and also improve soil filth, increase water holding capacity, lessen water and wind erosion, improve aeration, and promote soil biological activity. Supplementing the nutrient requirement of crops through organic fertilizer such as crop residues, manures and compost plays a key role in sustaining soil fertility and crop productivity. In most part of the tropics, socio-economic constraints and lack of scientific knowledge or adequate system of management of soil fertility push most of the farmers to little or no use of fertilizers. Rahman et al.(2006) reported that the moisture content, $\mathrm{pH}$, organic matter, organic carbon, nitrogen and $\mathrm{C} / \mathrm{N}$ in the residential area range between 25.38-34.13, 6.2-7.2, 35.75-43.03, 24.89-30.11, 1.43-1.91 and 15-19, respectively. Moreover, according to Holmer (2002), the $\mathrm{C} / \mathrm{N}$ was found 13-23, 11-13, 40-60, 9-25 in kitchen waste, vegetable wastes, leaves, grass, respectively. The application of residential or household organic solid waste can be a potential alternative of expensive chemical fertilizers and thus eventually a sustainable mean of SWM (Sujauddin et al., 2007). Mycorrhiza allowed the plants to derive more nutrients and enhance plant growth. Similar study was conducted by Marschner and Dell (1994) and Clark and Zeto (2000) stated that mycorrhizal fungi can overcome nutrient limitation to plant growth by enhancing nutrient acquisition, especially phosphorus. Robson et al., (1981) reported that mycorrhiza have the potential to uptake of most essential nutrients. $\mathrm{P}$ acts as a stimulator of plant growth and plays a vital role in nodule formation. The effects of $\mathrm{P}$ on nodulation and nitrogenous activity were often ascribed to a general stimulation via plant growth (Jakobsen, 1985; Yang, 1995; Reddell et al., 1997). However, some investigations suggested that $\mathrm{P}$ had a specific stimulation on different plant nodulations (Israel, 1987; Hellsten and Huss-Danell, 2000).

Vallini and Pera (1989) examined plant growth by application of mature compost in soil. But the application of fresh organic solid waste as a stimulating agent for plant growth has not yet been undertaken. Owing to this, the present study was an attempt to evaluate the plant growth and essential nutrients uptake by forest crops applying fresh household organic waste as an alternative option for conventional SWM. To observe the initial growth performance and macro nutrient uptake of Acacia auriculiformis and Cedrela toona using the household solid waste inoculated with mycorrhizal soil were the aim of this research.

\section{Materials and Methods}

The experiment was carried out in the nursery of the Institute of Forestry and Environmental Sciences, Chittagong University (IFESCU), Bangladesh. Experimental plot of $5 \times 3 \mathrm{~m}^{2}$ size was designed. The plot was divided into two subplots with $1 \mathrm{~m}$ spacing between two subplots. Living roots infected with mycorrhizal fungi and different types of glomus species in the soil were used as inoculums. The fungus infected root were sliced into small pieces with scissors and mixed thoroughly 
with the soil. The mixture was then used as mycorrhizal inoculums in waste. Solid wastes were collected from the residential area of Chittagong university campus, which then segregated into decomposable and non-decomposable waste. The decomposable waste included the residue of vegetables, paper, packaging material, fish residue, fruits residue, straw, etc. The seedlings were collected from the nursery of IFESCU. Two first growing species Akashmoni (Acacia auriculiformis) and Toon (Cedrela toona) were selected for the experiment. Three treatments were designed as $\mathrm{T}_{0^{-}}$ control, $\mathrm{T}_{1}$-soil with waste and $\mathrm{T}_{2}$-soil with mycorrhiza inoculated waste for the experiment. Size of each hole in the experimental plot was $30 \mathrm{~cm}$ in depth and $30 \mathrm{~cm}$ in diameter. The decomposable solid wastes were placed into the hole with bucket. $6 \mathrm{~kg}$ waste was used in each hole.

In case of treatment $\mathrm{T}_{2}$, at first $1 \mathrm{~kg}$ of waste was poured into the hole with the help of a bucket and then two inch layer of soil containing living roots infected with mycorrhizal fungi and different types of glomus species were placed. For treatment $\mathrm{T}_{1}$ only soil was used in between the waste layers. The same process was repeated twice and finally the holes were covered with two inch layer of soil. After that the seedlings were planted. Watering was carried out regularly in the morning. Regular removal of weeds, grasses etc. were done as far as possible. Partial shade and covering was provided to protect the seedlings from strong sunlight and rain. Morphological parameters of the seedlings, i.e. height, collar diameter and leaf number, were recorded before planting in the experiment plot.

The seedlings were allowed to grow for five months from the time of planting. After six months, seedlings were harvested and morphological parameters of shoot and root length, collar diameter, leaf number, branch number, nodulation status, fresh weight of leaves and the same of shoot and root were recorded. Leaf, shoot and root were dried in the oven at a temperature of $70^{\circ} \mathrm{C}$ for 24 hours. Finally the dry weight of leaf, shoot and root were recorded. The leaves were then grind in such that the leaves became powdery and then allowed to pass through sieve. The sieved leaves were then ready for determining nutrient status. Phosphorous was measured by Olsen's method; Potassium was determined by flame photometer; and Nitrogen was determined by micro-kjeldhal digestion process (Jackson, 1973). The data obtained in respect of different treatments were tested with ANOVA to find out the growth variations at $5 \%$ significant level.

\section{Results and Discussion}

\subsection{Fresh and dry weight of shoot, root and leaves of Acacia auriculiformis}

The highest fresh weight of shoot was found $598 \mathrm{~g}$ whereas the lowest was found $257 \mathrm{~g}$ (Figure 1). Fresh weight of shoot was recorded highest in $T_{2}$ and lowest in $T_{1}$. In case of dry weight better result was recorded also in $\mathrm{T}_{2}$ and it was $262 \mathrm{~g}$ whereas the lowest $(242 \mathrm{~g})$ dry weight of shoot was found in $\mathrm{T}_{0}$. In case of fresh weight, significant difference was found in between $\mathrm{T}_{0}$ and $\mathrm{T}_{1}$ and in between $\mathrm{T}_{0}$ and $\mathrm{T}_{2}$. But no significant difference (at $5 \%$ significance level) was found in between $\mathrm{T}_{1}$ and $\mathrm{T}_{2}$ whereas, dry weight values of all the treatments $\mathrm{T}_{0}, \mathrm{~T}_{1}$ and $\mathrm{T}_{2}$ were significantly different.

The highest fresh weight of root was recorded $204 \mathrm{~g}$ whereas the lowest fresh weight of root was found $81 \mathrm{~g}$ (Figure 2). Fresh weight of root was recorded highest in $\mathrm{T}_{2}$ and lowest in $\mathrm{T}_{1}$. In case of dry weight, better result was recorded also in $\mathrm{T}_{2}$ and it was $69 \mathrm{~g}$ whereas the lowest dry weight of root was found in $\mathrm{T}_{0}$ and it was $28 \mathrm{~g}$. Significant difference was found in the fresh weight values between $\mathrm{T}_{0}$ and $T_{1}$ but no significant difference found between $T_{1}$ and $T_{2}$. In case of dry weight, significant differences were recorded among all the treatments $\left(\mathrm{T}_{0}, \mathrm{~T}_{1}\right.$ and $\left.\mathrm{T}_{2}\right)$. 


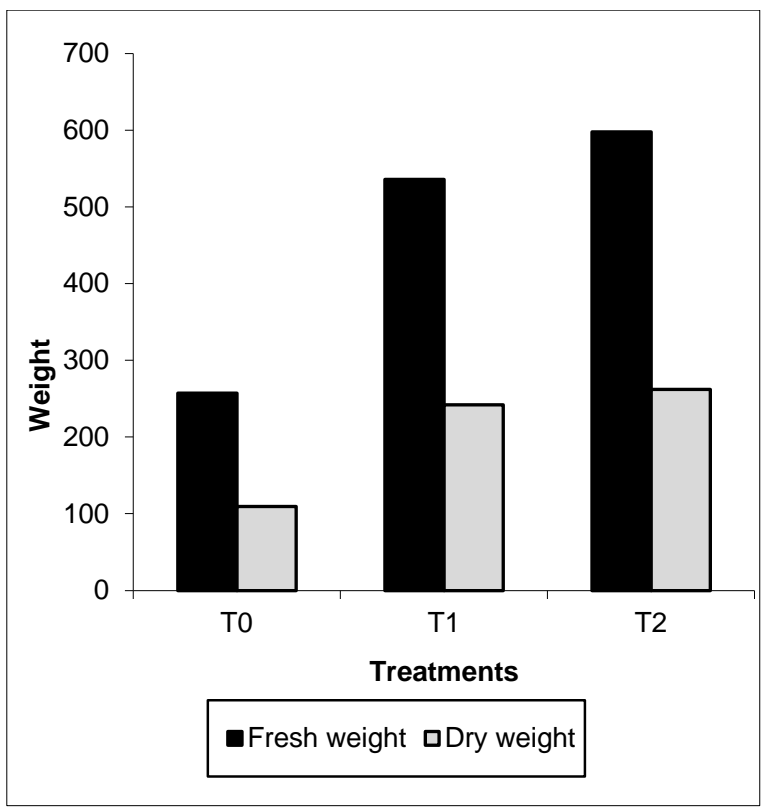

Figure 1: Fresh and dry weight of shoot of Acacia auriculoformis.

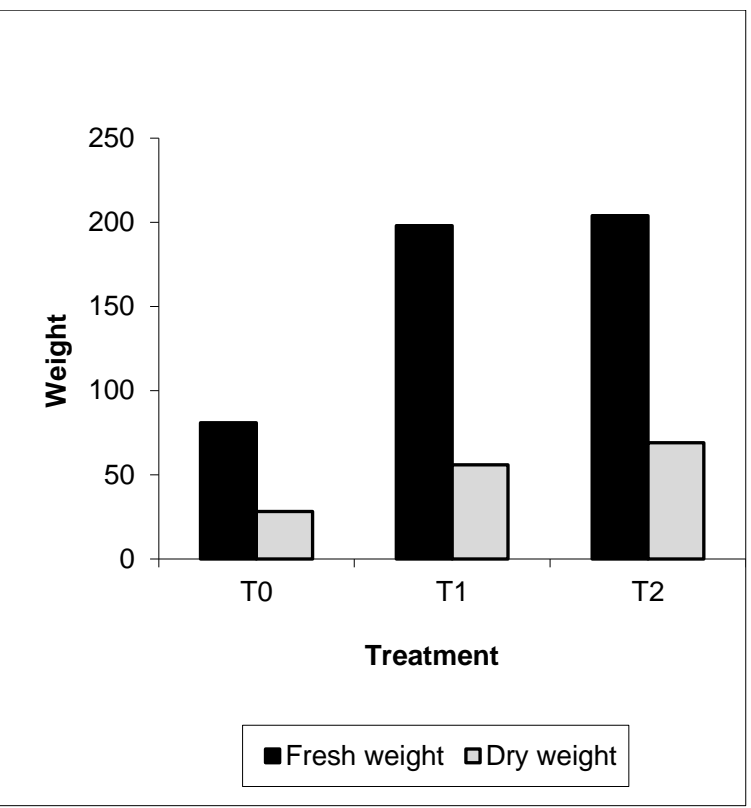

Figure 2: Fresh and dry weight of root of Acacia auriculiformis.

The highest fresh weight of leaf was recorded $790 \mathrm{~g}$ in $\mathrm{T}_{2}$, whereas the lowest fresh weight of leaf was observed $340 \mathrm{~g}$ in $\mathrm{T}_{0}$ (Figure 3 ). Similarly better result for dry weight of leaf was recorded also in $\mathrm{T}_{2}(102 \mathrm{~g})$ whereas the lowest was found in $\mathrm{T}_{0}(83 \mathrm{~g})$. In case of fresh weight significantly variation was found between $T_{0}$ and $T_{1}$. Significantly difference was also recorded between $T_{1}$ and $T_{2}$. In case of dry weight no significant result was recorded among the treatments $\mathrm{T}_{0}, \mathrm{~T}_{1}$ and $\mathrm{T}_{2}$.

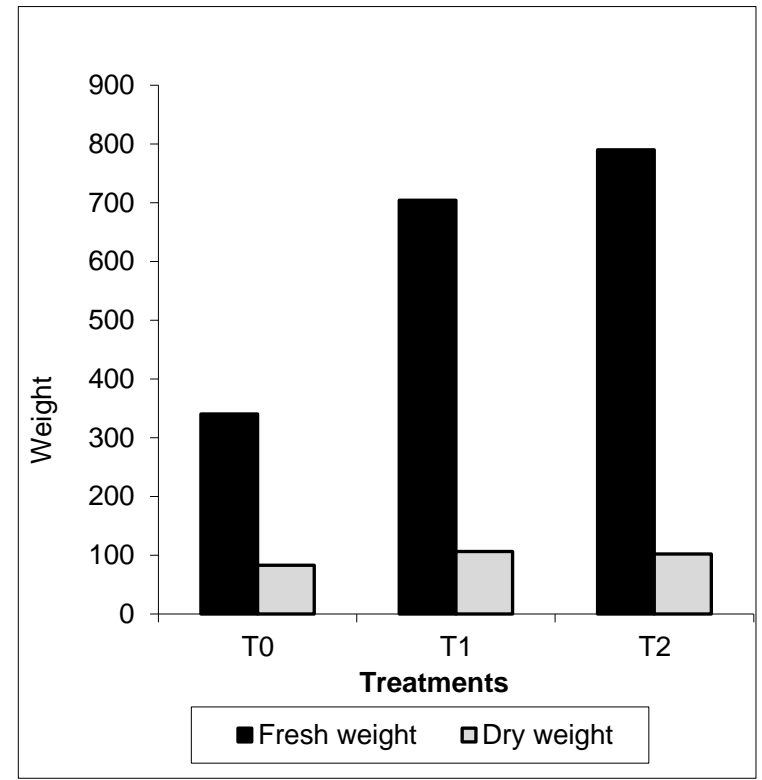

Figure 3: Fresh and dry weight of leaf of Acacia auriculiformis.

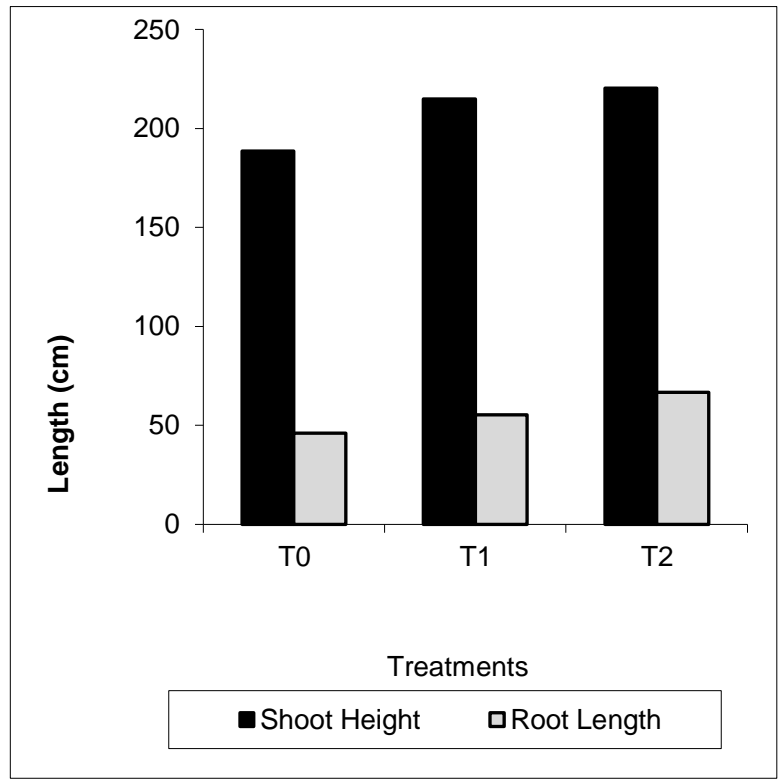

Figure 4: Root length and Shoot height of Acacia auriculiformis. 


\subsection{Root length and shoot height of Acacia auriculiformis}

The highest performance of shoot height was recorded $220.40 \mathrm{~cm}$ in $\mathrm{T}_{2}$, whereas the lowest shoot height was recorded $188.60 \mathrm{~cm}$ in $\mathrm{T}_{0}$ (Figure 4). In case of root length better result was recorded also in treatment $T_{2}(66.60 \mathrm{~cm})$, whereas the lowest dry weight of root was found in treatment $\mathrm{T}_{0}(46$ $\mathrm{cm})$.

\subsection{Number of leafy branch and nodule of Acacia auriculiformis}

The highest number of leaf was recorded 530.80 in $\mathrm{T}_{2}$ whereas the lowest number of leaf was found 234.80 in $\mathrm{T}_{1}$ (Figure 5). In case of branch number better result was recorded in treatment $\mathrm{T}_{1}$ and it was 33.80 whereas the lowest number of leaf was observed in $\mathrm{T}_{0}$ (17.60). Nodule number was found the highest in treatment $\mathrm{T}_{2}$ (208) while the lowest number of nodule was recorded in treatment $\mathrm{T}_{0}(91)$. In case of leaf number and branch number no significant result was recorded among the treatments. But nodule number varied significantly in between treatments $T_{0}$ and $T_{1}$ and in between $T_{0}$ and $T_{2}$.

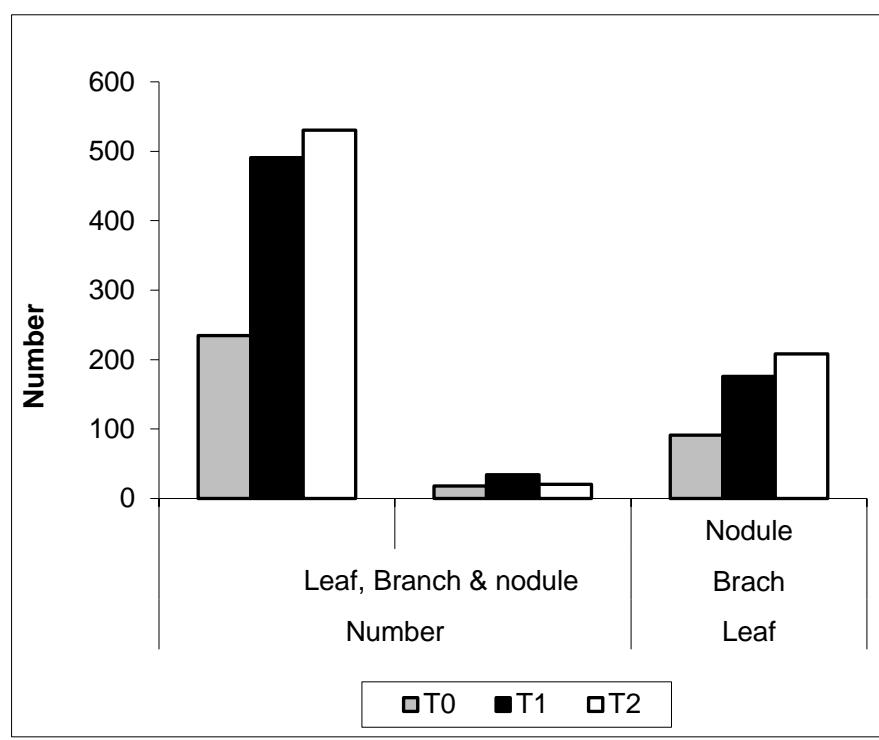

Figure 5: Number of leaf branch and nodule of Acacia auriculiformis.

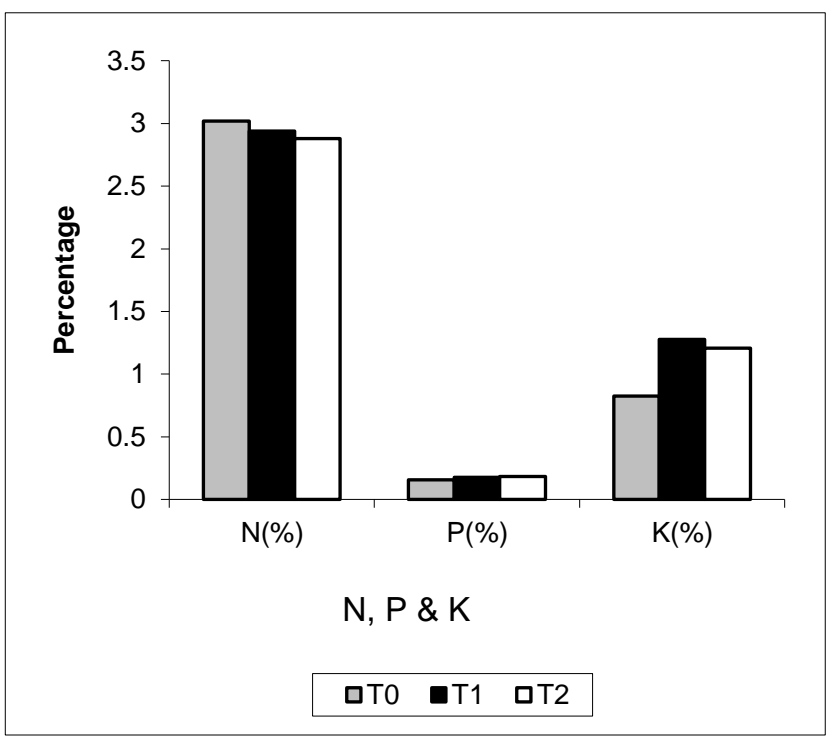

Figure 6: Percentage of N, P and K of Acacia auriculiformis.

\subsection{Percentage of $N, P$ and $K$}

Percentage of nitrogen uptake was found the highest in treatment $\mathrm{T}_{0}(3.02 \%)$ and the lowest in treatments $\mathrm{T}_{2}(2.88 \%)$ (Figure 6). Nitrogen uptake did not vary significantly among the treatments. Phosphorus uptake was highest in treatment $\mathrm{T}_{2}(0.18 \%)$ and lowest in treatment $\mathrm{T}_{0}(0.15 \%)$. Potassium uptake was highest in treatments $\mathrm{T}_{1}(1.27 \%)$ and lowest in treatment $\mathrm{T}_{0}(0.82 \%)$. Nitrogen uptake did not vary significantly among the treatments. But the potassium uptake varies significantly among the treatments $\mathrm{T}_{0}, \mathrm{~T}_{1}$ and $\mathrm{T}_{2}$.

\subsection{Fresh and dry weight of shoot, root and leaves of Cedrela toona}

The highest fresh weight of shoot was recorded $880 \mathrm{~g}$ in $\mathrm{T}_{2}$, whereas the lowest fresh weight of shoot was found $738 \mathrm{~g}$ in $\mathrm{T}_{0}$ (Figure 7). In case of dry weight better result was recorded also in $\mathrm{T}_{2}$ and it was $406 \mathrm{~g}$. No significant result was observed in among the treatments. 


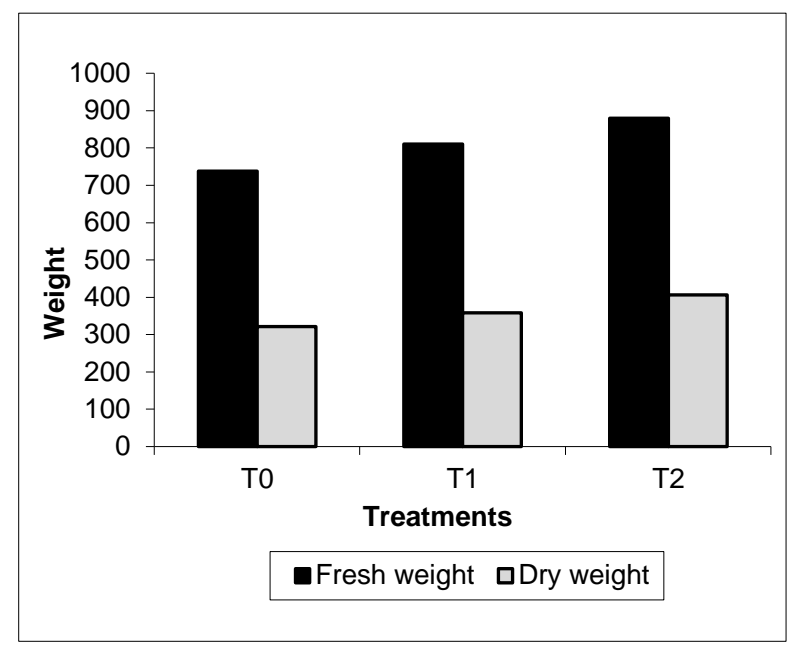

Figure 7: Fresh and dry weight of shoot of Cedrela toona.

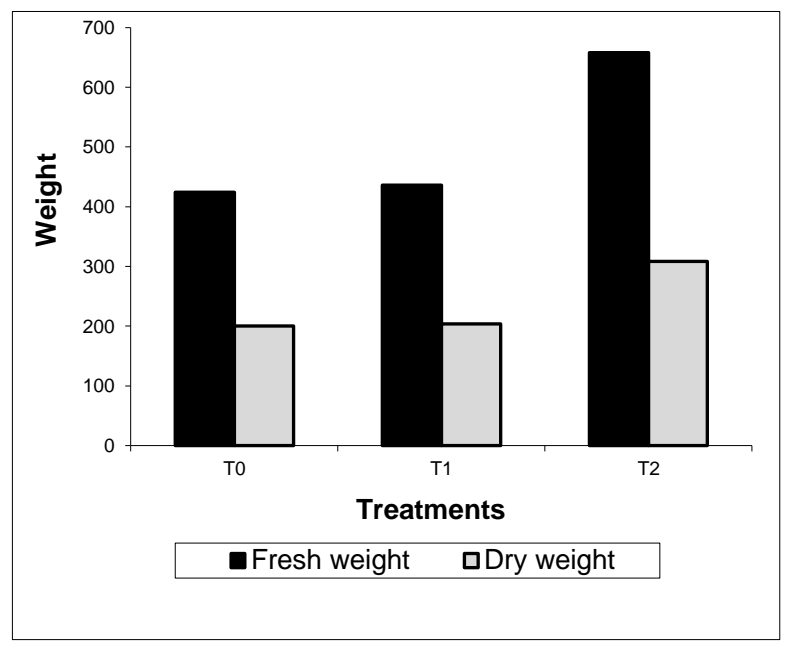

Figure 8: Fresh and dry weight of root of Cedrela toona.

The highest fresh weight of root was recorded $658 \mathrm{~g}$ in $\mathrm{T}_{2}$, whereas the lowest fresh weight of shoot was calculated $424 \mathrm{~g}$ in $\mathrm{T}_{0}$ (Figure 8). In case of dry weight better result was recorded also in $\mathrm{T}_{2}$ and it was $308 \mathrm{~g}$. No significant result was observed among the treatments. The highest fresh weight of leaf was recorded $482 \mathrm{~g}$ in $\mathrm{T}_{2}$ whereas the lowest fresh weight of leaf was recorded $326 \mathrm{~g}$ in $\mathrm{T}_{0}$ (Figure 9). In case of dry weight better result was recorded also in $\mathrm{T}_{2}(222 \mathrm{~g})$, whereas the lowest in $\mathrm{T}_{0}(144 \mathrm{~g})$. No significant result was observed among the treatments.

\subsection{Root length and shoot height of Cedrela toona}

Highest performance of shoot height was recorded $268.40 \mathrm{~cm}$ in treatment $\mathrm{T}_{1}$, whereas the lowest shoot height was found $240.2 \mathrm{~cm}$ (Figure 10). In case of root length better result was recorded in treatment $\mathrm{T}_{2}(82.40 \mathrm{~cm})$, whereas the lowest dry weight of root was observed in treatment $\mathrm{T}_{0}(66.20$ $\mathrm{cm})$. In case of shoot height, significant result was found among the three treatments, whereas no significant difference was found in root height among the treatments.

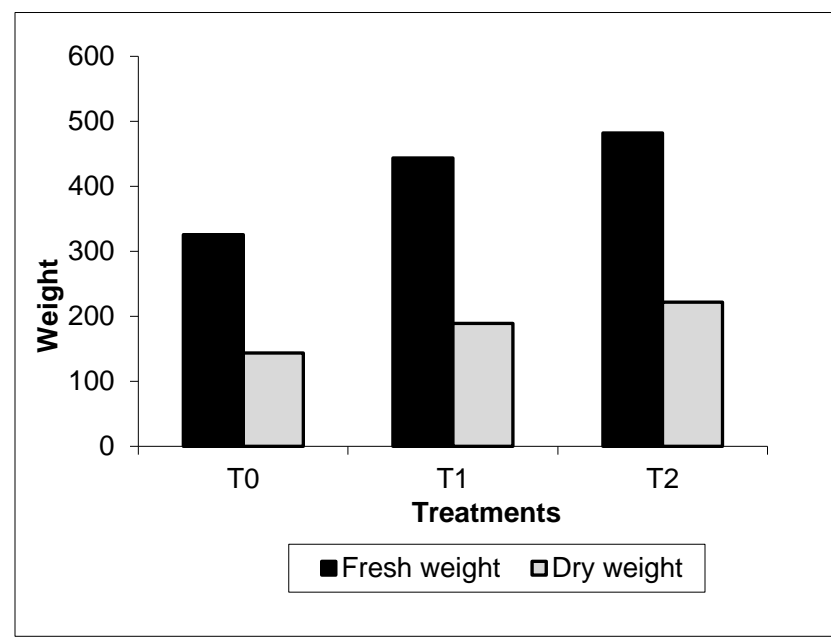

Figure 9: Fresh and dry weight of leaf of Cedrela toona.

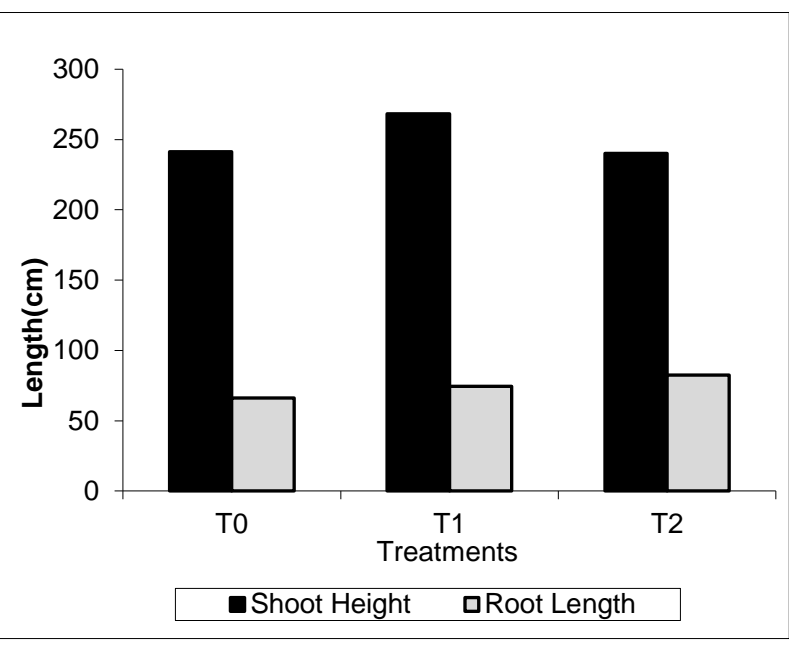

Figure 10: Root length and Shoot height of Cedrela toona. 


\subsection{Number of leaf and branch of Cedrela toona}

The highest number of leaf was recorded 1059.80 in $\mathrm{T}_{2}$ whereas the lowest number of leaf was found 840.00 in $\mathrm{T}_{0}$ (Figure 11). In case of branch number better result was recorded in treatment $\mathrm{T}_{2}$ and it was 44.80. In case of leaf number and branch number no significant difference was found among the treatments.

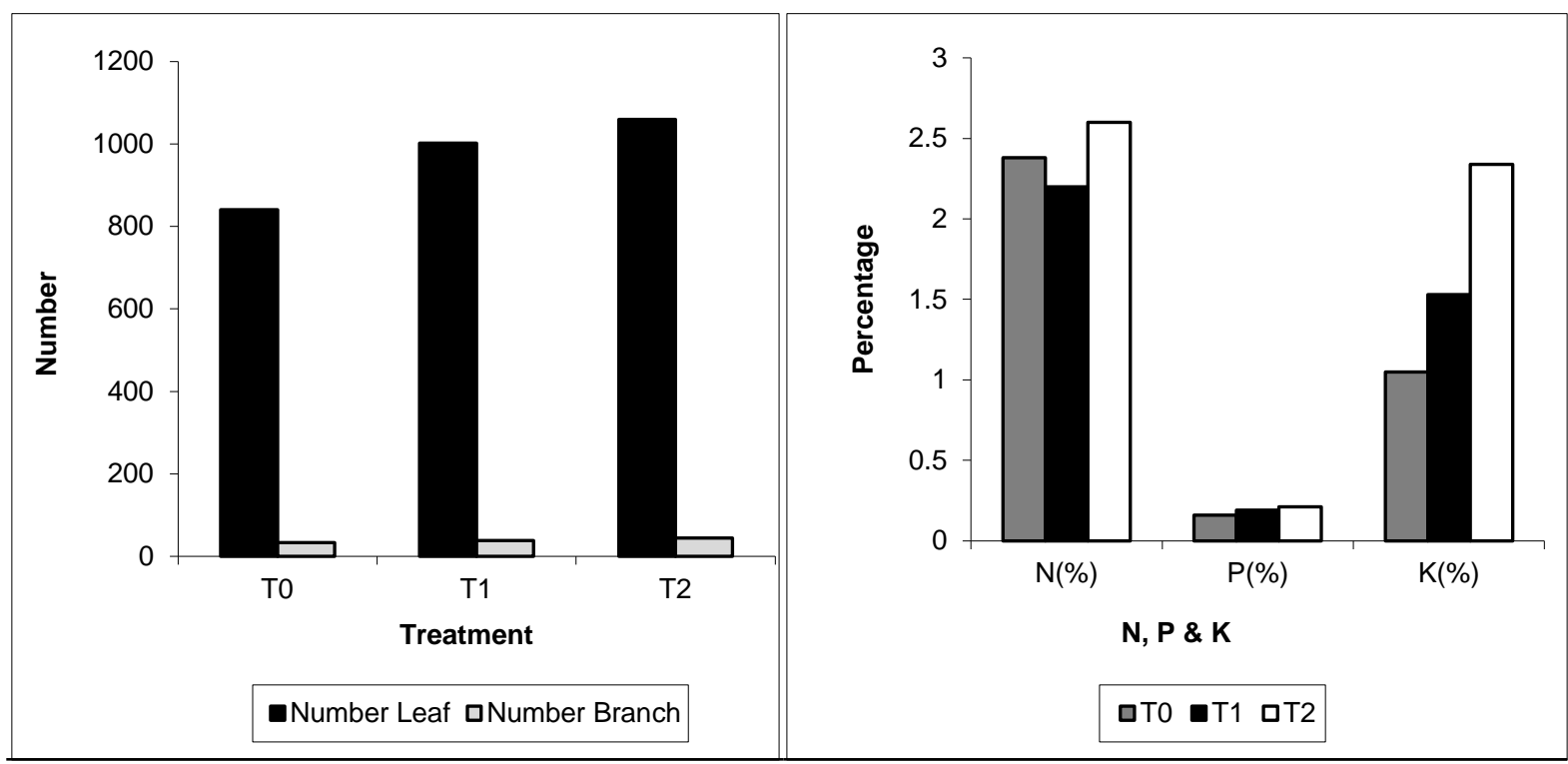

Figure 11: Number of leaf \& branch Cedrela toona.

Figure 12: Percentage of N, P and K of Cedrela toona.

\subsection{Percentage of $N, P$ and $K$ of Cedrela toona}

Percentage of nitrogen uptake was the highest in treatments $\mathrm{T}_{2}$ and it was $2.60 \%$. Nitrogen uptake was lowest in treatments $\mathrm{T}_{1}$ and it was $2.20 \%$ (Figure 12). Nitrogen uptake varies significantly among the treatments. Phosphorus uptake was highest in treatment $\mathrm{T}_{2}(0.21 \%)$ and lowest in treatment $\mathrm{T}_{0}(0.16 \%)$. Potassium uptake was highest in treatment $\mathrm{T}_{2}(2.34 \%)$ and lowest in treatment $\mathrm{T}_{0}(1.05 \%)$. Nitrogen, potassium and phosphorus uptake vary significantly among the treatments.

\section{Discussion}

In this study it is clearly found that the application of solid waste increases the overall plant growth. Cheung et al. (2000) observed more plant productivity in sewage sludge compost-amended lagoon ash in compared with vermiculite because compost can contribute large amount of plant nutrients. The major morphological criteria used to describe the seedling quality are shoot height and root length. Height and stem diameter increment are good traits for selecting leguminous plant (Duguma and Tonye, 1994). Consequently these morphological indicators of plant were found correlated with the effect of solid waste inoculated with mycorrhizal soil. Mycorrhiza is mutualistic associations between fungi and plant roots. They are described as symbiotic because the fungus receives photosynthetically derived carbon compounds and the plant has increased access to mineral nutrients (Brundrett et al., 1996). The solid wastes that are placed in the experimental hole were decomposed gradually. As a result the nutrients become available to the plants and showed better growth. Mistry et al. (2003) reported better biomass growth in the experiments of organic manure on 
tomato yield. Lloyd (2002) showed that most of the total nitrogen pool tied up by the soil microbes but the proportion immobilized by the microbes was higher in plots mulched with pellets than in the bare soil or composed yard waste. Baduruddin et al. (1999) assessed that wheat yield was better in the plots where organic fertilizer was applied in the form of farm yard manure.

Mycorrhiza allowed the plants to derive more nutrients and enhance plant growth. Present study revealed that fresh and dry weight of shoot was higher in treatment treated with mycorrhizal soil both in Acacia auriculiformis and Cedrela toona. Many other experiments have shown that mycorrhizal fungi can overcome nutrient limitation to plant growth by enhancing nutrient acquisition, especially phosphorus (Marschner and Dell, 1994; Clark and Zeto, 2000).

In the present study nodule number was found better in soil with waste $\left(\mathrm{T}_{1}\right)$ and in soil with waste inoculated with mycorrhiza $\left(\mathrm{T}_{2}\right)$ than the control $\left(\mathrm{T}_{0}\right)$. Similar result was also stated by Iqbal et al. (2007). In their study it was revealed that nodulation status and growth parameters were varied significantly in the soil amended with sludge in comparison to control. They found that the highest number of nodule was recorded from soil amended with residential sludge (1:1). In case of growth parameters, the highest growth was recorded from soil and residential sludge (1:1) combination compared to control.

Leaf number and number of branch were found higher in treatment with waste and highest performance was observed in treatment treated with waste and mycorrhiza. Mycorrhiza accelerate nutrient uptake especially phosphorus. The results are in accordance with the findings of Jasper et al., 1989 and Guissou et al., 1998. It has been established that in P-deficient soil mycorrhizas is an important factor for successful establishment of Acacia spp. (Jasper et al., 1989). This symbiotic association enhances the growth and the mineral nutrition of the host plant (Guissou et al., 1998).

Plant growth in terms of shoot height, root length and nodulation status were observed best in treatment $\mathrm{T}_{2}$ (waste inoculated with mycorrhiza). The mycorrhiza provides $\mathrm{P}$ to plants which acts as a stimulator of plant growth and plays a vital role in nodule formation. Selivanovskaya and Latypova, 2006 found the same outcome. They stated that the beneficial effects on the biomass of seedlings and the height of the shoots as well as on the length of the roots of the pine seedlings were greater in plots with composted sludge. Plants engaged in symbiotic $\mathrm{N}_{2}$ fixation generally have a high requirement for P (Robson 1983; Jungk, 1998), which was mainly contributed by high ATP requirements for nitrogenase function (Ribet and Drevon, 1996; Al Niemi et al.,1997), plus P needs for signal transduction, membrane biosynthesis, and nodule development and function (Graham and Vance, 2000). $P$ has been shown to increase plant growth and stimulate nodulation in legumes (Gates 1974; Gates and Wilson, 1974; Robson et al., 1981; Jakobsen, 1985; Israel, 1987; Hellsten and Huss-Danell 2000) as well as in other plants (Ekblad and Huss-Danell 1995; Yang 1995; Reddell et al., 1997). The effects of $\mathrm{P}$ on nodulation and nitrogenase activity were often ascribed to a general stimulation via plant growth (Robson et al., 1981; Jakobsen 1985; Yang 1995; Reddell et al., 1997). However, some investigations suggested that $\mathrm{P}$ had a specific stimulation on different plant nodulations (Israel 1987; Hellsten and Huss-Danell 2000).

Fresh weight of shoot, root and leaf showed better performance in waste inoculated with mycorrhizal soil and soil with waste over control. Similar works was done by Iqbal et al., 2007. 
According to his findings growth parameters (shoot and root length, vigor index, collar diameter, leaf number, fresh and dry weight of shoot and root and total dry biomass increment) and nodule formation of seedlings recorded from different combinations of sludge treatments in L. leucocephala varied significantly compared to control.

In case of nutrient uptake highest percentage of nitrogen uptake was observed in control in Acacia auriculiformis. Potassium uptake by Acacia auriculiformis was highest in treatment $\mathrm{T}_{1}$ (waste inoculated soil) and by Cedrela toona in treatment $\mathrm{T}_{2}$ (waste inoculated with mycorrhiza). Mycorrhiza inoculated with the waste provides $\mathrm{P}$ to the plants and thus the $\mathrm{P}$ uptake was highest in $\mathrm{T}_{2}$. This finding is consistent with the study of Marschner and Dell, 1994 and Clark and Zeto, 2000.

\section{Conclusion}

Large amount of solid waste, generated every day in Bangladesh, causes serious environmental hazards. The solid waste management practice should be in such that it should be feasible and economically viable. Various human introduced techniques are practiced in Bangladesh to use the unwanted and unusable waste in a productive way. The management of solid waste through composting involves high cost and as a result the farmer loses their interest in composting. This study revealed that seedling growth performance in terms of shoot height, root length, number of leaf and branch number and nodulation status was higher in treatment treated with waste and waste inoculated with mycorrhiza over control. In regards of nutrient uptake better performance was observed in treatments treated with waste and mycorrhiza. Solid waste contains organic matter and gradually releases macro and micronutrients to plants. It also increases soil filth, boost up the water holding capacity of sandy soil and promotes the growth of earth warms and other beneficial soil organisms which promote plant growth. In addition mycorrhiza provides $\mathrm{P}$ to the plants. According to the expert, $\mathrm{P}$ accelerates the availability of other nutrients like $\mathrm{K}$ and $\mathrm{N}$ and ultimately contributes to plant growth. Residential waste provides a potential source of nutrients to the forest crops especially fast growing species. So, the farmers could practice this method to ensure the low cost and hygienic disposal of solid waste. It will provide better performance in P deficient soil. This technology can be applied in fellow land planting and in vegetable gardening. The process may be practiced in horticulture and other agricultural crops after proper investigation on those crops.

\section{Reference}

Al Niemi, T.S., Kahn, M.L. and McDermott, T.R. 1997. P metabolism in the bean Rhizobium tropici symbiosis. Plant Physiol, 113: 1233-1242.

Baudriddin, M. Reynolds, M.P. and Ageeb, O.A.A. 1999. Agron. J., 91: 975-993.

Brundrett, M., Bougher, N., Dell, B., Grove, T. and Malajczuk, N. 1996. Working with Mycorrhizas in Forestry and Agriculture. ACIAR Monograph 32, p 374. Australian Centre for International Agricultural Research, Canberra.

Cheung, K.C., Wong, J.P.K., Zhang, Z.Q., Wong, J.W.C. and Wong, M.H. 2000. Revegetation of lagoon ash using the legume species Acacia auriculiformis and Leucaena leucocephala. Environmental Pollution, 109: 75-82.

Clark, R.B. and Zeto, S.K. 2000. Mineral acquisition by arbuscular mycorrhizal plants.

Dugma, B. and Tonye, J. 1994. Growth of ten multipurpose tree species on acid soil in Sangmelina, Camerron. Agroforestry systems, 27: 107-119. 
Ekblad, A. and Huss-Danell, K. 1995. Nitrogen fixation by Alnus incana and nitrogen transfer from $A$. incana to Pinus sylvestris influenced by macronutrients and mycorrhiza. New Phytologist, 131: 453-459.

Enayetullah, I., Sinha, A.H.M.M. and Khan, S.S.A. 2005. Urban Solid Waste Management Scenario of Bangladesh: Problems and Prospects. Waste Concern Technical Documentation, Dhaka, Bangladesh, p18.

Gates, C.T. 1974. Nodule and plant development in Stylosanthes humilis H.B.K.: symbiotic response to phosphorus and sulphur. Australian Journal of Botany, 22: 45-55.

Gates, C.T. and Wilson, J.R. 1974. The interaction of nitrogen and phosphorus on growth, nutrient status and nodulation of Stylosanthes humilis H.B.K. Townsville stylo. Plant and Soil, 41: 325333.

Graham, P.H. and Vance, C.P. 2000. Nitrogen fixation in perspective: an overview of research and extension needs. Field Crops Research, 65: 93-106.

Guissou, T.B.A.M., Oud, B.A.J.M., Guinko, S. and Duponnois, R. 1998. Responses of Parki biglobosa (Jacq.) Benth, Tamarindus indica L. and Zizyphus mauritiana Lam. to arbuscular mycorrhizal fungi in a phosphorus-deficient soil. Biology and Fertility of Soils, 26: 194-198.

Hellsten, A. and Huss-Danell, K. 2000. Interaction effects of nitrogen and phosphorus on nodulation in red clover (Trifolium pratense L.). Acta Agriculturae Scandinavica B, 50: 135-142.

Holmer, R.J. 2002. Basic principles for composting of biodegradable household wastes. Paper presented at the Urban Vegetable Gardening Seminar, Sundayag Sa Amihanang Mindanao Trade Expo, Cagayan de Oro City, Philippines, August 30.

Iqbal, G.M.A., Huda, S.M.S., Sujauddin, M. and Hossain, M.K. 2007. Effects of sludge on germination and initial growth performance of Leucaena leucocephala seedlings in the nursery. J. Forestry Research, 18(3): 226-230.

Israel, D.W. 1987. Investigation of the role of phosphorus in symbiotic dinitrogen fixation. Plant Physiology, 84: 835-840.

Jackson, 1973. Nitrogen transformation in soil organic matter. Technical meeting on the use of isotopes in soil organic matter studies. FAO/IAEA, Brunswick, USA.

Jakobsen, I. 1985. The role of phosphorus in nitrogen fixation by young pea plants (Pisum sativum). Physiologia Plantarum, 64: 190-196.

Jasper, D.A., Abbott, L.K. and Robson, A.D. 1989. Acacia auriculiformis respond to additions of phosphorus and to inoculation with VA mycorrhizal fungi in soils stockpiled during mineral sand mining. Plant and Soil, 115: 99-108.

Jungk, A.O. 1998. Dynamics of nutrient movement at the soil-root interface. In: Y. Waisel et al. (Eds.), Plant Roots: the Hidden Half. New York: Marcel Dekker, pp. 529-556.

Kumar, P.D. and Bhowmick, G.C. 1998. Solid waste management: the obvious answer. in: Roy, D. (Ed.), Environment Management with Indian Experience. A.P.H. Publishing Corporation, New Delhi, p.173.

Lloyd, J.H., Stinner, E.D.A. and Hoitink, B.R. 2002. Organic mulches enhance plant growth.

Marschner, H. and Dell, B. 1994. Nutrient uptake in mycorrhizal symbiosis. Plant and microbial biomass, activity and pine seedlings in nursery forest. Waste Management, 26: 1253-1258.

Mistry, K.K., Pani, B. and Khair, A. 2003. Effects of organic manure on yield of tomato in summer season under polythene tunnel. J. annual botanical conference, pp. 44. 
Rahman, M.A., Alam, M.S. and Al-Amin, M. 2006. Segregation of Biodegradable Solid Waste of Chittagong Metropolitan Area Based on Specific Physical and Chemical Properties. Pakistan Journal of Biological Sciences, 9(3): 460-464.

Reddell, P., Yang, Y. and Shipton, W.A. 1997. Do Casuarina cunninghamiana seedlings dependent on symbiotic $\mathrm{N}_{2}$ fixation have higher phosphorus requirement than those supplied with adequate fertilizer nitrogen? Plant and Soil, 189: 213-219.

Ribet, J., and Drevon, J.J. 1996. The phosphorus requirement of $\mathrm{N}_{2}$ fixing and urea-fed Acacia mangium. New Phytol, 132: 383-390.

Robson, A.D. 1983. Mineral nutrition. in: Broughton, W.J. (Ed.), Nitrogen Fixation of Legumes. Oxford, UK: Clarendon Press, 3: 36-55.

Robson, A.D., O’Hara, G.W. and Abbott, L.K. 1981. Involvement of phosphorus in nitrogen fixation by subterranean clover (Trifolium subterraneum). Australian Journal of Plant Physiology, 8: 427-436.

Selivanovskaya, S.Y. and Latypova, V.Z. 2006. Effects of composted sewage sludge on microbial biomass, activity and pine seedlings in nursery forest. Waste Management, 26: 1253-1258.

Sinha, A.H.M. and Enayetullah, M.I. 2000. Community based solid waste management: the Asian experience. Dhaka, Bangladesh: Waste Concern and USAID.

Sujauddin, M., Huda, S.M.S. and Hoque, A.T.M.R. 2007. Household solid waste characteristics and management in. Chittagong, Bangladesh. Waste Management, 28: 1688-1695.

Vallini, G. and Pera, A. 1989. Green compost production from vegetable waste separately collected in metropolitan garden-produce market. Biological Wastes, 29(1): 33-41.

World Bank, 1999. What a Waste: Solid Waste Management in Asia, Washington DC, USA, p. 43.

Yang, Y. 1995. The effects of phosphorus on nodule formation in the Casuarina- Frankia symbiosis.

Plant and Soil, 176: 161-169. 